\title{
Flagellate Erythema Secondary to Bleomycin for Non- Seminomatous Testis Tumor
}

\author{
Felipe de Lacerda Pereira 1*, Alexandre Protzner Morbeck 2
}

\author{
${ }^{1}$ Medical School, University Center of Brasilia, Federal District, DF, Brazil. \\ ${ }^{2}$ Medical Oncology, Sírio-Libanês Hospital, Federal District, DF, Brazil.
}

*Corresponding author: Felipe de Lacerda Pereira. Octogonal 4, BI F, 116. Zip Code: 70660-046 Federal District, DF, Brazil. Phone: 55 (61) 9 9947-7400. E-mail: felipelacerdape@gmail.com

Research Ethics Committee Approval (if necessary): We declare that the patient approved the study by signing an informed consent form and the study followed the ethical guidelines established by the Declaration of Helsinki.

Received on: Jul 23, 2021. Accepted on: Aug 03, 2021. Available online: Aug 5, 2021.

Abstract
The development of flagellate erythema secondary to bleomycin treatment is a rare
adverse effect. The prevalence varies between 8 to $22 \%$ of patients and it is
becoming rarer. Flagellate erythema presents as a scaly erythematous papule. A
lower amount of bleomycin hydrolase in regions with reduced production, such as
skin and lungs, decreases bleomycin degradation, which allows its accumulation in
tissues, triggering an inflammatory process, especially in patients with lower basal
enzyme function. We report a clinical case of a severe presentation of flagellate
erythema secondary to a patient ongoing bleomycin, etoposide and platinum (BEP)
based chemotherapy of non-seminomatous testis cancer.
Keywords: Bleomycin; Flagellate Erythema; Adverse Effect; Chemotherapy; Testis
cancer.

\section{Introduction}

Bleomycin (BLM) is an antineoplastic antibiotic that can fragment DNA [1]. This process leads to greater cell cycle interruption and accumulation at the G2 cell division phase. BLM mechanism of action is most likely related to compromising the interaction of oxygen and iron $\left(\mathrm{Fe}^{+2}\right)$. Exposed to reducing agents and oxygen, activates the metallobleomycin complex, which works as a ferrous oxidase inside the cells. BLM associates with amines located in terminal DNA regions, leading to the activation of reactive oxygen species, degrading DNA chains [2]. BLM metabolization occurs through 
Flagellate erythema secondary to bleomycin for non seminomatous testis tumor

its inactivation mediated by a cytosolic cysteine hydrolase, called bleomycin hydrolase. The availability of this enzyme varies through the body tissues and is usually lower in the skin and lungs. However, patients with lower than usual tissue levels of the enzyme may accumulate the drug substance, in its undegraded form, in susceptible body tissues, especially the skin [3]. Thus, its accumulation in the dermis may trigger the development of typical skin lesions, called flagellate erythema. In some older studies, the prevalence ranged from $8 \%$ to $22 \%$ and its turning rarer because of its limited clinical use [4]. This article reports this unusual adverse effect in the context of treating a non-seminomatous testis cancer.

\section{Case report}

A-20 years old male patient presents painless testicular nodule. His past medical history is relevant for depression, orchitis and hypertension. He had ultrasonography showing hypoechoic areas. Tumor markers were evaluated at the time of the presentation: LDH 291, AFP 1, 21 and HCG 63. Also magnetic resonance (MRI) of scrotum presented left intratesticular infiltration. Left Orchiectomy was performed and non-seminomatous neoplasia was found (pT2pN1M0, S1). The immunohistochemistry panel for testicular cancer was done and the results were compatible with embryonal carcinoma.
Adjuvant treatment was started with $30 \mathrm{UI}$ of bleomycin, $201 \mathrm{mg}$ of etoposide and 40,2 $\mathrm{mg}$ of cisplatin (BEP), for 3 cycles. After the first dose of BLM he started with progressive, diffuse, severe and pruritic erythematous papules (Figures 1-5), associated with an itchy aspect at the beginning of treatment, and worsening.

Diagnosis of flagellate erythema was done, followed by treatment with prednisone and antihistamines, with consequent improvement of the lesions. The patient completed two cycles without bleomycin (EP). On follow up, the patient had presented a significant improvement of the pruritus. Nowadays he is under a complete remission of the disease.

\section{Discussion and Conclusion}

Flagellate erythema is a rare adverse effect [4]. Characteristic lesions with erythematous papule formation, associated with linearly shaped plaques were found diffusely in the patient's body, affecting the trunk, head, upper and lower limbs [5] This condition may develop in any of the drug administration forms [6]. Flagellate erythema usually manifests in both men and women within the first 72 ours of drug use. In contrast, this case report presents a clinical manifestation on the eighth day of the medication [4]. The mechanism of this adverse effect is probably on the increase of melanogenesis, pigmentary incontinence due to the inflammatory 
process and toxic effects of the drug itself, such as neutrophilic eccrine hidradenitis [7].

In the majority of cases of flagellate erythema, the resolution is spontaneous, however, as in this case, the high intensity of the skin manifestation inflammatory response required the use of oral corticosteroids, antihistamines and permanent discontinuity of the drug [3]. Heat in the compromised regions may recurrently lead to worsening of cases. Cooling the chemotherapy before its administration may be a way to alleviate the severity of cases [8]. The patient presented in this clinical case had clinical improvement of the erythematous condition and after a few weeks the bleomycin was interrupted.

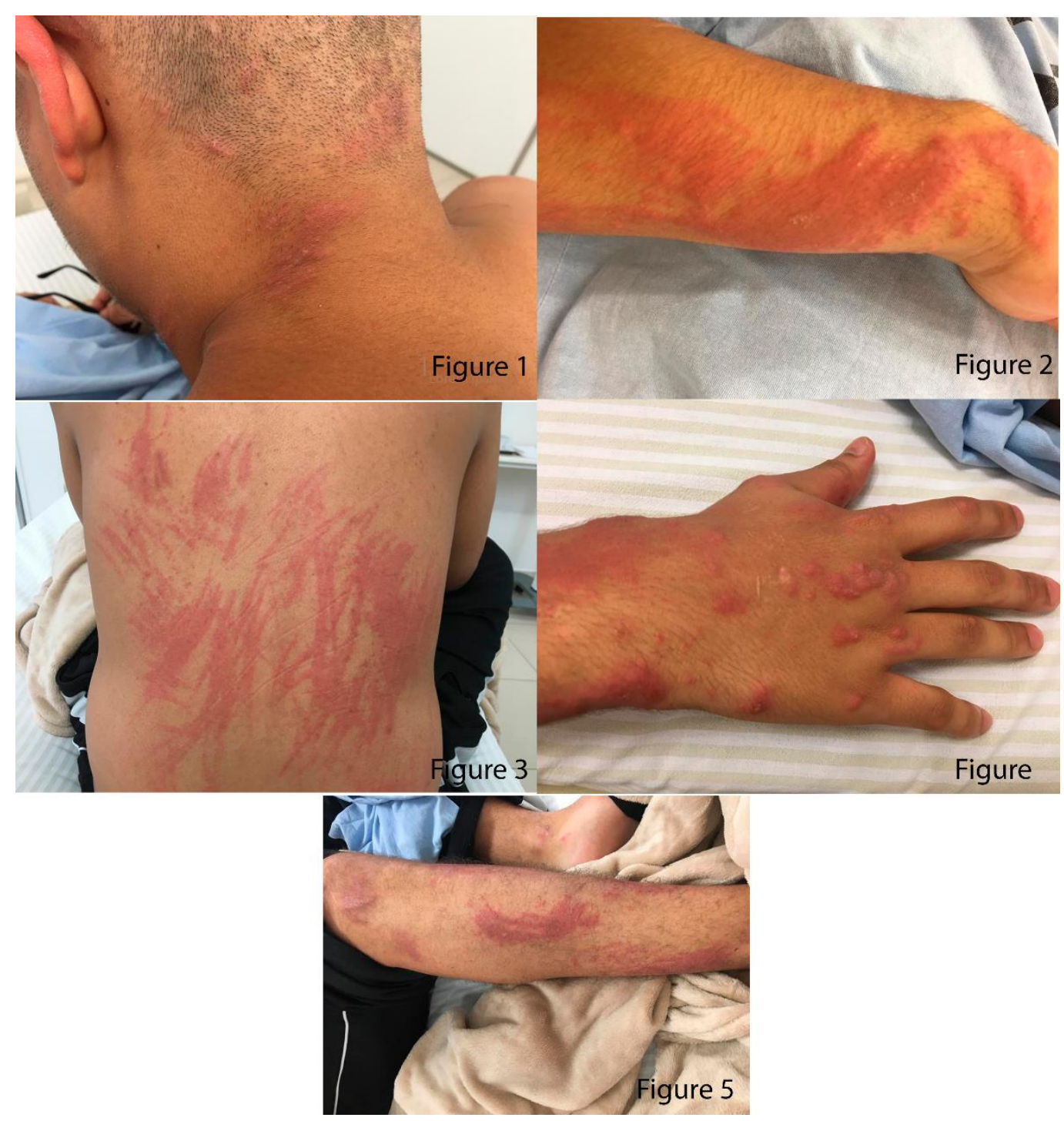

Figure 1: 1. Low back flagellate erythema. 2. Forearm flagellate erythema. 3. Head and neck flagellate erythema. 4. Right hand flagellate erythema. 5. Right leg flagellate erythema. 


\section{References}

[1] McEvoy GK, American Society of Health-System Pharmacists. AHFS Drug information 2008. Bethesda, Md.: American Society of Health-System Pharmacists; 2008.

[2] Gilman AG, Goodman LS, Nies AS, organizadores. Goodman and Gilman's the pharmacological basis of therapeutics. 8. ed. New York: McGrawHill; 1993. 1811 p.

[3] Yamamoto T. Bleomycin and the skin. Br J Dermatol. novembro de 2006;155(5):869-75.

[4] Ziemer M, Goetze S, Juhasz K, Elsner P. Flagellate Dermatitis as a BleomycinSpecific Adverse Effect of Cytostatic Therapy: A Clinical-Histopathologic Correlation. Am J Clin Dermatol. fevereiro de 2011;12(1):68-76.

[5] Chen Y-B, Rahemtullah A, Breeden E, Hochberg EP. Bleomycin-Induced Flagellate Erythema. J Clin Oncol. 1 ${ }^{\circ}$ de março de 2007;25(7):898-900.

[6] Fyfe A, McKay P. Toxicities associated with bleomycin. J R Coll Physicians Edinb. 13 de setembro de 2010;40(3):213-5.

[7] Al-Khenaizan S, Al-Berouti B. Flagellate pigmentation: a unique adverse effect of bleomycin therapy. Eur
J Dermatol EJD. fevereiro de 2011;21(1):146.

[8] Polla L, Mérot Y, Slosman D, Polla B, Olgiati D, Saurat JH. [Linear pigmentogenic dermitis after scintigraphy using bleomycin]. Ann Dermatol Venereol. 1985;112(10):821-3.

Conflict of interest: The authors declare no conflicts of interest.

Acknowledgements: None.

Funding: None.

How to cite this article: Pereira FL, Morbeck AP. Flagellate Erythema Secondary to Bleomycin for NonSeminomatous Testis Tumor. Brazilian Journal of Case Reports. 2021 Jul-Sep; 01(3):86-89. 